\title{
Aminoácidos, minerais, vitaminas e a saúde do casco dos bovinos
}

\author{
Amino acids, minerals, vitamins, and cattle hoof health
}

\author{
Paulo José Bastos Queiroz ${ }^{1 *}$, Bruno Moraes Assis ${ }^{1}$, Danilo Conrado Silva ${ }^{1}$, Aline Vanessa Estrela Dantas ${ }^{1}$, \\ Rogério Elias Rabelo², Luiz Antônio Franco da Silva ${ }^{1}$ \\ ${ }^{1}$ Universidade Federal de Goiás (UFG), Goiânia, GO, Brasil \\ 2 Universidade Federal de Goiás (UFG), Jataí, GO, Brasil
}

\section{Resumo}

As doenças digitais ocasionam grandes prejuízos à bovinocultura, pois causam dor e resultam em claudicação que, por sua vez, promove redução do bemestar animal e compromete a produtividade. As afecções podais em bovinos também ocasionam prejuízos relacionados a gastos com tratamento medicamentoso e cirúrgico, redução da fertilidade e descarte precoce de animais. A estrutura e a qualidade do casco dependem de um adequado processo de queratinização, que é influenciado pelo satisfatório suprimento de nutrientes como aminoácidos, lipídios, vitaminas e minerais. A deficiência de nutrientes importantes para a formação do estojo córneo promove síntese de tecido queratinizado de baixa qualidade e com maior suscetibilidade a danos químicos, físicos e microbianos. Dessa forma, a nutrição é importante para a formação de um estojo córneo resistente e, também, para a redução da incidência de doenças digitais em bovinos. Diante disso, objetivouse com o presente artigo fazer uma revisão sobre a implicação dos aminoácidos, minerais e vitaminas para a saúde do casco bovino.

Palavras-chave: Doenças digitais. Macroelementos. Microelementos. Unhas. Nutrição.

\begin{abstract}
Hoof diseases in cattle lead to appreciable economic losses of production as they cause pain and lameness, impacting animal welfare and, consequently, productivity. Bovine lameness increases the production costs because of the cost associated with medication or surgical treatments; decreases fertility; and necessitates early slaughter of high-value animals. The structure and quality of the hoof depend on an adequate keratinization process, which is influenced by nutrient supply to cattle, such as amino acids, lipids, vitamins, and minerals. Deficiency of key nutrients
\end{abstract}


responsible for the growth of the hoof capsule results in the synthesis of low-quality keratinized tissue with elevated susceptibility to chemical, physical, and microbial damages. Therefore, high-quality nutrition is mandatory for the development of a resistant hoof capsule and for the reduction of the incidence of bovine hoof diseases. The aim of the current review was to provide an overview of the important of amino acids, minerals, and vitamins that aid the maintenance of a healthy cattle hoof.

Keywords: Digital diseases. Macroelements. Microelements. Hoof. Nutrition.

\section{Introdução}

As doenças digitais ocasionam grande prejuízo à bovinocultura no Brasil e no mundo. Essas enfermidades causam dor e resultam em claudicação que, por sua vez, promove redução do bem-estar animal e compromete a produtividade. As afecções podais em bovinos também ocasionam prejuízos relacionados a gastos com tratamento medicamentoso e cirúrgico, redução da fertilidade e descarte precoce de animais.

0 casco tem a função de transferir para o sistema musculoesquelético o impacto do membro locomotor do animal ao apoiar-se no solo. Além disso, essa estrutura protege as camadas proliferativas da epiderme e o leito capilar da derme contra lesões físicas, químicas e biológicas (Zhang et al., 2007). A qualidade do tecido córneo que compõe o casco depende de uma queratinização adequada. Assim, para que isso acorra, o processo de diferenciação das células epidérmicas necessita de um adequado suprimento de aminoácidos, lipídios, minerais e vitaminas (Muelling, 2009). Dessa forma, doenças podais como a laminite e deficiências nutricionais afetam a nutrição da epiderme queratinizada, comprometendo a diferenciação dos queratinócitos e a produção de tecido córneo (Greenough, 2007).

Dentre os nutrientes necessários para o processo de queratinização estão os aminoácidos, principalmente a cisteína, ácidos graxos como o linoleico e o ácido araquidônico, macroelementos como o cálcio (Ca), microelementos como o zinco (Zn), e as vitaminas, com destaque para a biotina (Lean et al., 2013). Portanto, o fornecimento de quantidades adequadas de nutrientes importantes para a qualidade do casco é fundamental para a formação de um tecido córneo resistente, o qual protegerá a derme e as outras estruturas internas do estojo córneo mesmo diante de ambientes desafiadores.

0 presente trabalho objetivou fazer uma revisão de literatura sobre aminoácidos, minerais e vitaminas importantes para a saúde do casco bovino.

\section{Morfologia e nutrientes importantes para a qualidade do estojo córneo}

O casco ou estojo córneo é constituído pela muralha, sola, bulbo e linha branca. A muralha pode ser dividida em abaxial e axial. A primeira possui formato convexo e pode, ainda, ser subdividia nas porções dorsal e lateral. A muralha axial é voltada para a região interdigital e apresenta formato côncavo (König e Liebich, 2004) (Figura 1A). A sola e o bulbo completam a estrutura anatômica externa do estojo córneo (Mülling e Budras, 2011). A sola do casco é plana e apresenta uma área côncava na face axial, a qual não entra em contato com o solo. A conexão entre a sola e a muralha do casco é realizada pela linha branca, que é constituída por tecido córneo macio que possibilita uma junção flexível entre essas duas estruturas (König e Liebich, 2004) (Figura 1B).

0 casco é formado pelo processo dinâmico de queratinização das células epidérmicas, no qual ocorre a diferenciação celular dos queratinócitos (Muelling, 2009). 0 produto final da queratinização é o estrato córneo, camada mais externa da epiderme, formada por células repletas de filamentos de queratina (Eurell e Frappier, 2006). A estrutura e, consequentemente, a qualidade do tecido córneo que compõe o casco dependem de uma boa queratinização e esta, por sua vez, necessita de um adequado suprimento de nutrientes (Mülling et al., 1999). Os aminoácidos e os macro e microelementos são importantes para a resistência do estojo córneo. Além disso, os minerais também estão envolvidos em diversas vias metabólicas que promovem a proliferação e diferenciação dos queratinócitos. As vitaminas, por sua vez, atuam como antioxidantes e cofatores envolvidos na diferenciação celular em todos os tecidos córneos (Tomlinson et al., 2004). 


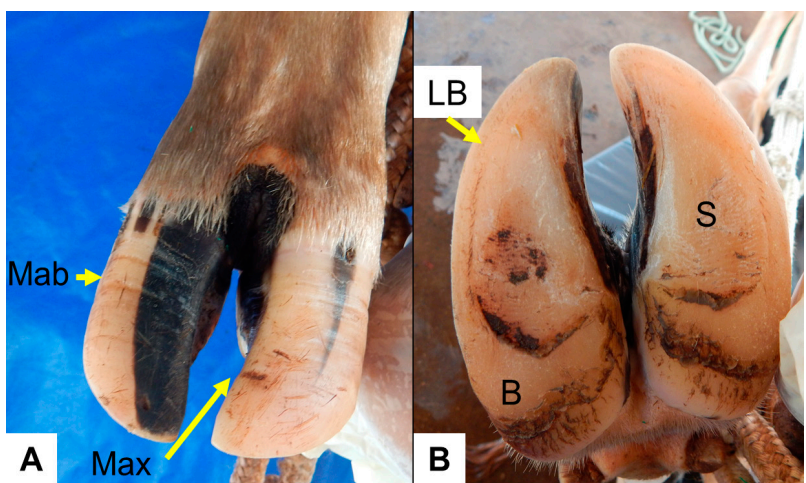

Nota: Foto de Paulo José Bastos Queiroz.

Figura 1 - Estojo córneo bovino. (A): Mab = muralha abaxial; Max = muralha axial. $(B): B=$ bulbo; $L B=$ linha branca; $S=$ sola.

\section{Aminoácidos}

Os aminoácidos sulfurados cisteína e metionina são considerados os mais importantes para a formação da queratina dura que constitui o estojo córneo (Tomlinson et al., 2004). A cisteína desempenha uma função fundamental na estrutura das proteínas, pois é capaz de formar pontes de enxofre com outros aminoácidos, também conhecidas como pontes dissulfeto (Haag et al., 2012). As queratinas duras possuem alta concentração de cisteína e numerosas pontes dissulfeto entre as cadeias polipeptídicas, as quais proporcionam grande resistência e estabilidade ao tecido córneo (Shetty e Gokul, 2012). As regiões do estojo córneo de maior dureza, em escala decrescente, são muralha, sola e bulbo. Essa diferença na rigidez é ocasionada pela maior concentração de cisteína nas regiões mais rígidas do casco (Galbraith et al., 2006).

Os aminoácidos sulfurados são importantes para a formação do envelope cornificado, pois unem as proteínas involucrinas também por meio de pontes dissulfeto (Mülling et al., 1999). 0 envelope cornificado é formado durante a diferenciação terminal dos queratinócitos e é constituido por várias proteínas estruturais, que são unidas por ligações covalentes (Yamane et al., 2016). Esse complexo proteico se deposita na face interna da membrana plasmática dos queratinócitos, fornecendo resistência mecânica e proteção contra enzimas proteolíticas (Akiyama, 2017). Em situações de deficiência de aminoácidos sulfurados na dieta ocorrem alterações estruturais no envelope cornificado, as quais tornam os queratinócitos mais suscetíveis ao desenvolvimento de lesões (Mülling et al., 1999).

A metionina, embora em menor concentração no tecido córneo, também é considerada um aminoácido limitante para a síntese de queratina dura (Livesey e Laven, 2007). Entretanto, nas pesquisas em que foi realizada a suplementação desse aminoácido, não se observou efeito significativo sobre a qualidade do casco (Galbraith et al., 2006; Livesey e Laven, 2007). Novilhas lactantes foram suplementadas com $15 \mathrm{~g} / \mathrm{dia}$ de metionina protegida durante 13 semanas após o parto. Esse tratamento não promoveu alterações significativas nas taxas de crescimento e desgaste do casco (Livesey e Laven, 2007). Nessas mesmas condições experimentais, o fornecimento de metionina protegida também não promoveu redução da incidência de hemorragias de linha branca e sola (Laven e Livesey, 2004). Em outro estudo, novilhas prenhes foram suplementadas com 5 a $6 \mathrm{~g} /$ dia de metionina protegida durante a gestação. Esse tratamento também não promoveu efeito na dureza do casco ou na concentração dos aminoácidos cisteína e metionina em diferentes regiões do estojo córneo (Galbraith et al., 2006).

\section{Minerais}

\section{Cálcio (Ca)}

O Ca desempenha um papel importante no processo de diferenciação dos queratinócitos (Deo e Deshmukh, 2018). A presença de Ca na epiderme é fundamental para o início da diferenciação dos queratinócitos e para a formação de estruturas de contato intercelular. Mais especificamente, o Ca possibilita a formação de desmossomos e outros tipos de junções intercelulares, que unem os queratinócitos. Além disso, o estímulo ao receptor de cálcio dá início aos mecanismos intracelulares necessários para a diferenciação (Bikle et al., 2012).

Durante a cornificação, o Ca é essencial para a ativação das transglutaminases epidérmicas, que 
são enzimas que catalisam a formação de ligações cruzadas entre proteínas do substrato, as quais formam o envelope cornificado (Yamane etal., 2016). Dentre essas proteínas, as mais importantes são a involucrina, loricrina, periplaquina e envoplaquina (Deo e Deshmukh, 2018). Baixas concentrações sanguíneas de Ca reduzem a disponibilidade desse nutriente para os queratinócitos, o que diminui os níveis de diferenciação celular e formação de tecido córneo (Elsholz et al., 2014). Dessa forma, vacas em início de lactação apresentam significativa redução da concentração plasmática de $\mathrm{Ca}$ e, assim, diminuição do aporte desse elemento aos queratinócitos do casco, resultando em produção de tecido córneo de baixa qualidade (Tomlinson et al., 2004). Acredita-se que a baixa concentração de Ca no periparto esteja relacionada com a formação de sulcos semicirculares no casco de vacas recémparidas (Mülling et al., 1999; Greenough, 2007).

\section{Enxofre (S)}

A importância do S para a qualidade do tecido córneo está relacionada principalmente à presença desse íon nos aminoácidos cisteína e metionina (Tomlinson et al., 2004). Os íons S presentes nesses aminoácidos formam pontes dissulfeto entre as cadeias polipeptídicas, que são importantes para a estabilidade estrutural da queratina e de outras proteínas (Voet e Voet, 2011). O S também está presente no sulfato de condroitina das cartilagens e nas vitaminas tiamina e biotina, ambas do complexo B (NRC, 2001). Diante da importância do S para a qualidade do tecido córneo, é fundamental que esse mineral esteja presente em quantidades adequadas na dieta dos bovinos (Lean et al., 2013). Os aminoácidos sulfurados são uma importante fonte de enxofre para os bovinos. Assim, a proteção desses aminoácidos contra a degradação da microbiota ruminal pode auxiliar na maior absorção dos mesmos pelos ruminantes. Recomenda-se que a dieta de bovinos contenha $0,30 \%$ de $\mathrm{S}$ na matéria seca (MS) (NRC, 2001).

\section{Zinco (Zn)}

O Zn é um microelemento fundamental para a diferenciação e sobrevivência dos queratinócitos
(Inoue et al., 2014). Além disso, está envolvido em diversos processos metabólicos, tais como crescimento, ingestão alimentar, secreção de hormônios mitogênicos e expressão gênica (FagariNobijari et al., 2012). Esse nutriente atua em três funções específicas durante a queratinização, denominadas funções catalítica, regulatória e estrutural (Tomlinson et al., 2004). As enzimas catalíticas são metaloenzimas que dependem da presença do Zn para sua ativação, sendo estas enzimas componentes integrais na diferenciação dos queratinócitos. $0 \mathrm{Zn}$ é fundamental também para a enzima Cu-Zn-superóxido dismutase, que atua na prevenção da peroxidação lipídica (Lean et al., 2013).

Quanto à função regulatória, o Zn atua no controle das enzimas calmodulina e proteína-quinase $\mathrm{C}$, bem como na síntese do fosfato de inositol (NRC, 2001). A calmodulina é responsável pelo transporte de íons Ca para o citosol dos queratinócitos, processo importante para a ativação das transglutaminases epidérmicas durante a etapa final da queratinização (Lean etal., 2013). A proteína-quinase C, que também é dependente de $\mathrm{Ca}$, é responsável pela fosforilação de proteínas e, dessa forma, fornece energia para o processo de diferenciação dos queratinócitos. 0 fosfato de inositol é um mensageiro secundário, que promove aumento da concentração de Ca nas células por meio da mobilização das reservas desse nutriente no retículo endoplasmático (Tomlinson et al., 2004).

A função estrutural do Zn está relacionada, principalmente, à sua importância para a formação de proteínas estruturais durante a queratinização (Lean et al., 2013). Dentre essas, destacam-se as "proteínas dedo" de Zn (zinc finger proteins), que são domínios proteicos que contêm os aminoácidos cisteína e histidina unidos por um íon Zn. Essas estruturas proteicas interagem com ácidos nucleicos, outras proteínas e lipídios para facilitar uma infinidade de processos biológicos (Kluska et al., 2018). As "proteínas dedo" de Zn estão envolvidas na formação dos filamentos de queratina e, portanto, a deficiência de $\mathrm{Zn}$ pode reduzir a replicação dessas proteínas e comprometer a estabilidade estrutural do queratinócito (Tomlinson et al., 2004).

Alguns trabalhos têm demonstrado a importância do Zn para a saúde dos cascos, como foi observado em búfalos, onde a muralha dorsal e abaxial do 
casco apresentam maior concentração de Zn frente a outras regiões do casco, o que pode ser atribuído ao intenso crescimento dos queratinócitos e à maior resistência dessas regiões (Assis et al., 2017). Dessa forma, baixas concentrações desse microelemento podem comprometer a qualidade dos cascos e a produtividade animal, como demonstrado em um estudo que avaliou as concentrações plasmáticas de $\mathrm{Zn}$ em 10325 bovinos, provenientes de 2080 rebanhos comerciais na Europa, correlacionando a baixa concentração desse microelemento à menor produção leiteira e a problemas de locomoção (Enjalbert et al., 2006).

Do mesmo modo, em outros dois estudos, vacas com lesões podais apresentaram menor concentração de Zn no estojo córneo em comparação às vacas que não claudicavam (Kibar et al., 2016). Entretanto, uma pesquisa apresentou resultados conflitantes aos descritos anteriormente, pois nesta, a concentração sérica de Zn e a concentração deste no casco não apresentaram diferença significativa entre vacas saudáveis e vacas com claudicação moderada e severa (Sadeghi-Nasab et al., 2013). Contudo, o insuficiente fornecimento de $\mathrm{Zn}$ biodisponível durante o período periparto e durante a lactação de vacas leiteiras pode predispor a produção de tecido córneo de baixa qualidade no casco (Muelling, 2009). Nesses animais, a demanda por Zn é maior no final do período seco e durante a lactação, em virtude do estresse gerado pelo manejo intensivo e da alta exigência desse nutriente para a lactação. Logo, aconselha-se o incremento dos níveis de $\mathrm{Zn}$ na dieta durante esse período (Greenough, 2007).

Alguns estudos demonstraram que a suplementação com $\mathrm{Zn}$ promove melhora na qualidade do casco bovino. A suplementação de óxido de $\mathrm{Zn}$ para bovinos machos, durante 56 dias, na dose de $150 \mathrm{mg}$ de $\mathrm{Zn} / \mathrm{kg}$ de MS promoveu redução na ocorrência de claudicação (Fagari-Nobijari et al., 2012). Vacas leiterias de alta produção suplementadas durante cinco meses com $360 \mathrm{mg} /$ dia de $\mathrm{Zn}$, fornecido na forma de $\mathrm{Zn}$ metionina (orgânico), apresentaram redução nos casos de erosão de talão, avulsão de sola, lesões de linha branca e casco em saca rolha. Além disso, as vacas que receberam Zn metionina apresentaram menor incidência de crescimento excessivo da muralha abaxial do casco (Randhawa et al., 2012).

\section{Cobre (Cu)}

0 Cu é um microelemento que atua como cofator de diversas enzimas (NRC, 2001) e, assim como o Zn, está envolvido na síntese de queratina (Lean et al., 2013). No estojo córneo, o Cu é importante para o desenvolvimento de resistência, de forma que a concentração desse nutriente no tecido córneo do casco está relacionada à qualidade do mesmo (Assis et al., 2017). Dentre as enzimas que necessitam de $\mathrm{Cu}$, a thiol oxidase, também conhecida como sulfidril oxidase, é a que apresenta maior importância para a queratinização. Essa enzima é responsável pela formação das pontes dissulfeto entre os aminoácidos cisteína nos filamentos de queratina (Lean et al., 2013). Em situações de deficiência de $\mathrm{Cu}$ ocorre redução da atividade da enzima thiol oxidase e, consequentemente, redução da formação de pontes dissulfeto, que são importantes para a estabilidade da queratina (Goluch-Koniuszy, 2016).

O Cu também é necessário para a ativação da enzima Cu-Zn-superóxido dismutase, que tem função antioxidativa e contribui para a prevenção da peroxidação lipídica. A ação antioxidativa dessa enzima é importante principalmente na prevenção de lesões oxidativas aos lipídios insaturados, que constituem o cemento intercelular (Lean et al., 2013). A deficiência de $\mathrm{Cu}$ ou de outros nutrientes que predisponham o excessivo estresse oxidativo no cemento intercelular ocasiona síntese de tecido córneo de baixa qualidade e aumenta a suscetibilidade à ocorrência de fissuras e ao maior desgaste do casco (Tomlinson et al., 2004). Ademais, o Cu é necessário para a ativação da enzima citocromo oxidase, que é responsável pela transferência do elétron terminal na cadeia respiratória mitocondrial e, portanto, é indispensável para a geração de energia na célula (Suttle, 2010).

Vacas leiteiras com claudicação severa apresentaram níveis de $\mathrm{Cu}$ significativamente menores no soro sanguíneo e no casco em comparação às vacas saudáveis ou com claudicação moderada. Os autores atribuíram esse resultado a um desbalanço nutricional em virtude do excesso de $\mathrm{Zn}$ na dieta, visto que este pode comprometer a absorção e a utilização do $\mathrm{Cu}$ no organismo (Sadeghi-Nasab et al., 2013). Vacas com claudicação apresentaram menores níveis de $\mathrm{Cu}$ no soro 
sanguíneo, pelo e casco em comparação às vacas saudáveis (Zhao etal., 2015). Não foram encontrados estudos que avaliaram, especificamente, o efeito da suplementação ou deficiência de $\mathrm{Cu}$ sobre a qualidade do casco de bovinos.

\section{Selênio (Se)}

A principal função fisiológica do Se é participar como constituinte da enzima glutationa peroxidase, que tem função antioxidante e, portanto, promove remoção dos radicais livres do organismo (Lean et al., 2013). A glutationa peroxidase realiza a conversão do peróxido de hidrogênio $\left(\mathrm{H}_{2} \mathrm{O}_{2}\right)$ em água, atuando como um importante componente do sistema celular antioxidante (NRC, 2001). No tecido queratinizado do casco, a principal função do Se é evitar lesões oxidativas nos lipídios que formam o cemento intercelular, contribuindo para proteção e manutenção de sua integridade (Lean et al., 2013).

Quando a concentração de Se na dieta ou forragem se encontra abaixo de 0,25 ppm na MS, recomenda-se a suplementação desse micronutriente (Greenough, 2007). No entanto, o consumo excessivo de Se também pode ser prejudicial à queratinização (Lean et al., 2013). Em humanos, a intoxicação por Se pode ocasionar, dentre outros sintomas, anormalidades nas unhas e queda de cabelo. Esses sintomas têm sido atribuídos à ruptura da estrutura proteica da queratina, pois acredita-se que, quando em excesso no organismo, o Se integra as pontes dissulfeto, ocasionando a formação de tecido córneo frágil (Aldosary et al., 2012). Em bovinos, os sintomas da intoxicação crônica por Se incluem emagrecimento progressivo, alopecia, lesões no estojo córneo e claudicação (Suttle, 2010).

Em um estudo, avaliou-se os efeitos de três concentrações de Se na dieta $(0,15,0,35$ e 0,5 $\mathrm{mg} / \mathrm{kg}$ na MS), nas formas de selenito de sódio ou Se orgânico, quanto à qualidade do casco de bovinos confinados. Nessa pesquisa não houve diferença significativa entre as dietas avaliadas, entretanto os bovinos que receberam Se orgânico apresentaram um tendência para melhores níveis histológicos de qualidade da banda coronária em comparação aos grupos alimentados com selenito de sódio (Räber et al., 2008). Para vacas leiteiras, a recomendação de Se na dieta é de 0,3 mg/kg de MS. Casos de intoxicação crônica são observados com o consumo de 5 a $40 \mathrm{mg}$ de $\mathrm{Se} / \mathrm{kg}$ em um período de semanas ou meses (NRC, 2001).

\section{Manganês (Mn)}

A quantidade de Mn presente no organismo animal é extremante pequena. A principal função do Mn no organismo é a ativação de enzimas, dentre elas a piruvato carboxilase (PC) e a Mnsuperóxido dismutase (McDonald et al., 2010). A PC é importante para o metabolismo energético, pois é a primeira enzima da via da gliconeogênese e catalisa a conversão do piruvato em oxaloacetato (Voet e Voet, 2011). A presença de energia para a diferenciação dos queratinócitos e síntese de tecido córneo é fundamental para a qualidade do casco (Tomlinson et al., 2004). Além disso, a Mnsuperóxido dismutase exerce função antioxidante, a fim de minimizar o acúmulo de formas reativas do oxigênio, as quais podem ocasionar lesão celular (NRC, 2001). Em um estudo, observou-se que vacas com claudicação apresentaram menores níveis de Mn no soro sanguíneo, pelo e casco em comparação às vacas saudáveis (Zhao et al., 2015).

\section{Magnésio (Mg)}

Embora o Mg não seja considerado um mineral diretamente associado com claudicações em bovinos (Greenough, 2007), uma pesquisa recente demonstrou que bovinos com necrose de pinça (Toe Tip Necrosis Syndrome) apresentaram concentração de Mg significativamente menor na muralha e sola do casco em comparação aos animais controle. Os pesquisadores observaram que a redução de 10 ppm de $\mathrm{Mg}$ na muralha e sola do casco resultou em aumento da probabilidade de ocorrência de necrose de pinça (Jelinski et al., 2018). Em outro estudo, pesquisadores brasileiros observaram que vacas com lesões associadas à laminite apresentaram menor concentração de $\mathrm{Mg}$ na muralha abaxial do casco em comparação às vacas saudáveis (Barbosa et al., 2016). 


\section{Vitaminas}

\section{Biotina}

A biotina é uma vitamina do complexo $B$, que atua como cofator de algumas enzimas, as quais são denominadas de enzimas dependentes de biotina. As carboxilases dependentes de biotina são acetilCoA carboxilase (ACC), piruvato carboxilase (PC), propionil-CoA carboxilase (PCC) e $\beta$-metilcrotonilCoA carboxilase (Lietzan e St. Maurice, 2013). As enzimas PC e PCC estão envolvidas em vias metabólicas de produção de energia. A PC é a primeira enzima da via da gliconeogênese e a PCC é uma das enzimas envolvidas no metabolismo do ácido propiônico, principal precursor de glicose nos ruminantes (Murray et al., 2012).

A biotina é considerada a vitamina de maior importância para a quaratinização, pois está envolvida na síntese de queratina e na lipogênese (Tomlinson et al., 2004). As principais classes de lipídios que compõem o cemento intercelular são as ceramidas, o colesterol e os ácidos graxos livres (Meckfessel e Brandt, 2014). Dessa forma, a biotina tem grande importância para a formação e manutenção do cemento intercelular, pois participa da síntese de ácidos graxos de cadeia longa e dos lipídios que compõem essa matriz que une os queratinócitos (Lean et al., 2013).

A suplementação de $20 \mathrm{mg} /$ dia de biotina durante cinco meses promoveu aumento da quantidade de lipídios na sola do casco de vacas leiteiras. Nessa mesma pesquisa, os autores observaram aumento da densidade das ceramidas presentes na sola. Tais resultados foram associados ao aumento da qualidade do casco nos animais suplementados com biotina (Randhawa et al., 2008). Em outro estudo, a suplementação com biotina também promoveu aumento significativo da concentração de lipídios na sola do casco (Higuchi et al., 2004).

A indução de deficiência de biotina em bezerro ocasionou o desenvolvimento de várias lesões na pele e alterações estruturais no casco. A avaliação histológica da epiderme queratinizada do casco demonstrou interrupções espaciais e na coordenação temporal da queratinização. Observouse, também, marcante redução dos filamentos de queratina nas células epidérmicas. Observou-se síntese de semento intercelular de baixa qualidade, que resultou em ruptura progressiva da adesão intercelular entre os queratinócitos e, por fim, ocasionou a completa desintegração do estrato córneo (Mülling et al., 1999).

Vacas com lesões podais apresentaram menor concentração sérica de biotina em comparação às vacas saudáveis; resultado sugestivo de que a redução da concentração dessa vitamina no sangue pode afetar a qualidade do casco (Al-Qudah e Ismail, 2012). Novilhos suplementados com $12,5 \mathrm{mg} /$ dia de biotina durante 40 dias apresentaram aumento da taxa de crescimento da muralha do casco (Silva et al., 2010). Em outro estudo realizado pelo mesmo grupo de pesquisadores, a suplementação com $20 \mathrm{mg} /$ dia dessa substância para bezerras ocasionou menor desgaste da muralha do casco (Queiroz, 2017).

Uma meta-análise avaliou os resultados de estudos que investigaram o efeito da biotina sobre a qualidade do casco. Os autores concluíram que embora frequentemente as pesquisas demonstrem que a suplementação com biotina ocasione efeitos positivos para o casco, a maioria dessas pesquisas possuem delineamentos inconsistentes. Diante disso, sugerem a necessidade de mais estudos para quantificar os efeitos da suplementação dessa vitamina sobre a incidência de claudicação, bem como na prevenção de doenças podais específicas (Lean e Rabiee, 2011).

\section{Vitamina A}

A vitamina $\mathrm{A}$ ou ácido retinóico é um micronutriente que realiza funções importantes na reprodução, desenvolvimento fetal, crescimento e diferenciação celular, manutenção da integridade das células epiteliais e do sistema imune (Gonçalves et al., 2016). Sabe-se que essa vitamina desempenha uma função importante na manutenção da saúde da pele e do cabelo. Dessa forma, é razoável propor que ela também seja importante para a saúde do casco (Greenough, 2007). A vitamina A regula indiretamente a expressão gênica, o que pode explicar suas diversas funções (NRC, 2001). Dentre essas funções, é necessária para a diferenciação dos queratinócitos (Lean et al., 2013). Ainda, a deficiência de vitamina A pode estar associada a alterações nos epitélios cornificados, podendo 
ocasionar metaplasia escamosa (Deo e Deshmukh, 2018).

Vacas com claudicação moderada e severa apresentaram concentrações séricas de betacaroteno e vitamina A menores em comparação às sem claudicação. Nesse estudo, tanto os bovinos que claudicavam quanto os bovinos saudáveis apresentaram níveis séricos abaixo do ideal de betacaroteno e vitamina A. Segundo os autores, tal stiuação, junto de outros fatores de risco, pode comprometer a qualidade do casco (SadeghiNasab et al., 2013). Em outro estudo, vacas com claudicação severa apresentaram concentração sérica de retinol significativamente menor do que vacas sem claudicação (Seyrek et al., 2008).

\section{Vitamina D}

A importância da vitamina D para os tecidos queratinizados está associada a sua atividade regulatória na absorção de $\mathrm{Ca}$, que atua na diferenciação terminal dos queratinócitos (Bikle et al., 2012), como já mencionado. A vitamina D aumenta a absorção de Ca no intestino delgado, a mobilização de Ca dos ossos e reduz a excreção renal do mesmo (Thandrayen e Pettifor, 2018). A vitamina $\mathrm{D}$ atua, também, como fator de controle da diferenciação dos queratinócitos, pois, por meio de uma via autócrina, metabólitos ativos dessa vitamina reduzem a proliferação dos queratinócitos e aumentam a diferenciação celular (Deo e Deshmukh, 2018). A deficiência desse nutriente é rara em bovinos, entretanto, com o aumento do uso de sistemas de manejo intensivo na pecuária leiteira e com a redução da exposição à luz solar, os animais podem apresentar deficiências subclínicas de vitamina D (Tomlinson et al., 2004).

\section{Vitamina E}

A vitamina E é uma substância antioxidante e lipossolúvel, envolvida na manutenção da integridade de estruturas ricas em lipídios, como a membrana celular e o cemento intercelular no tecido córneo (Lean et al., 2013). Em associação com a glutationa peroxidase e outras enzimas antioxidantes, a vitamina protege células, enzimas e o material nuclear das células contra a ação de radicais livres. Essa proteção é particularmente importante na prevenção de oxidação dos ácidos graxos poli-insaturados, que atuam como constituintes primários de membranas subcelulares e precursores de prostaglandinas (McDonald et al., 2010).

\section{Conclusão}

Diversos trabalhos têm demonstrado aassociação entre claudicação e menores níveis de minerais, aminoácidos e vitaminas, tanto no sangue como nos cascos de bovinos. Deste modo, o fornecimento de quantidades adequadas de nutrientes essenciais para o processo de queratinização, com destaque para os aminoácidos sulfurados, os minerais cálcio e zinco e a vitamina biotina, é fundamental para a saúde do casco e, consequentemente, para a redução dos prejuízos relacionados à claudicação.

\section{Referências}

Akiyama M. Corneocyte lipid envelope (CLE), the key structure for skin barrier function and ichthyosis pathogenesis. J Dermatol Sci. 2017;88(1):3-9.

Aldosary BM, Sutter ME, Schwartz M, Morgan BW. Case series of selenium toxity from a nutritional supplement. Clin Toxicol (Phila). 2012;50(1):57-64.

Al-Qudah KM, Ismail ZB. The relationship between serum biotin and oxidant/antioxidant activities in bovine lameness. Res Vet Sci. 2012;92(1):138-41.

Assis BM, Vulcani VAS, Silva LAF, Dias M, Pancotti A, Lima CRO, et al. Biochemical composition of the hoof capsule of buffaloes and its influence on hoof quality. Arq Bras Med Vet Zootec. 2017;69(1):57-64.

Barbosa AA, Luz GB, Rabassa VR, Corrêa MN, Martins CF, Del Pino FAB. Concentration of minerals in the hoof horny capsule of healthy and lame dairy cows. Semina Ciêenc Agrarr. 2016;37(3):1423-130.

Bikle DD, Xie Z, Tu CL. Calcium regulation of keratinocyte differentiation. Expert Rev Endocrinol Metab. 2012;7(4):461-72. 
Deo PN, Deshmukh R. Pathophysiology of keratinization. J Oral Maxillofac Pathol. 2018;22(1):86-91.

Elsholz F, Harteneck C, Muller W, Friedland K. Calcium - a central regulator of keratinocyte differentiation in health and disease Eur J Dermatol. 2014;24(6):650-61.

Enjalbert F, Lebreton P, Salat O. Effects of copper, zinc and selenium status on performance and health in commercial dairy and beef herds: retrospective study. J Anim Physiol Anim Nutr (Berl). 2006;90(11-12):459-66.

Eurell JA, Frappier BL. Dellmann's textbook of veterinary histology. 6 ed. Iowa: Blackwell Publishing; 2006. 416 p.

Fagari-Nobijari H, Amanlou H, Dehghan-Banadaky M. Effects of zinc supplementation on growth performance, blood metabolites and lameness in young Holstein bulls. J Appl Anim Res. 2012; 40(3): 222-8.

Galbraith H, Rae M, Omand T, Hendry KA, Knight $\mathrm{CH}$, Wilde CJ. Effects of supplementing pregnant heifers with methionine or melatonin on the anatomy and other characteristics of their lateral hind claws. Vet Rec. 2006;158(1):21.

Goluch-Koniuszy ZS. Nutrition of women with hair loss problem during the period of menopause. Prz Menopauzalny. 2016;15(1):56-61.

Gonçalves A, Estevinho BN, Rocha F. Microencapsulation of vitamin A: a review. Trends Food Sci Technol. 2016;51:76-87.

Greenough P. Bovine laminitis and lameness: a hands on approach. St. Louis: Saunders Elsevier; 2007. 311 p.

Haag AF, Kerscher B, Dall'Angelo S, Sani M, Longhi R, Baloban $\mathrm{M}$, et al. Role of cysteine residues and disulfide bonds in the activity of legume root nodule-specific, cysteine-rich peptide. JBiolChem.2012;287(14):10791-8.

Higuchi H, Maeda T, Nakamura M, Kuwano A, Kawai K, Kasamatsu M, et al. Effects of biotin supplementation on serum biotin levels and physical properties of samples of solar horn of Holstein cows. Can J Vet Res. 2004;68(2):93-7.
Inoue Y, Hasegawa S, Ban S, Yamada T, Date Y, Mizutani $\mathrm{H}$, et al. ZIP2 protein, a zinc transporter, is associated with keratinocyte differentiation. J Biol Chem. 2014;289 (31):21451-62.

Jelinski M, Waldner C, Penner G. Case-control study of mineral concentrations of hoof horn tissue derived from feedlot cattle with toe tip necrosis syndrome (toe necrosis). Can Vet J. 2018; 59(3):254-60.

Kibar M, Leblebici Z, Caglayan T, Aksoy A. Is level of trace minerals important for healthy foof in dairy cows? Manas J Agr Vet Life Sci. 2016;6(2):14-21.

Kluska K, Adamczyk J, Krezel A. Metal binding properties of zinc fingers with a naturally altered metal binding site. Metallomics. 2018; 10(2):248-63.

König HE, Liebich HG. Veterinary anatomy of domestic mammals. Stuttgart: Schattauer; 2004. 681 p.

Laven RA, Livesey CT. The effect of housing and methionine intake on hoof horn hemorrhages in primiparous lactating Holstein cows. J Dairy Sci. 2004;87(4):1015-23.

Lean IJ, Rabiee AR. Effect of feeding biotin on milk production and hoof health in lactating dairy cows: a quantitative assessment. J Dairy Sci. 2011;94(3):1465-76.

Lean IJ, Westwood CT, Golder HM, Vermunt JJ. Impact of nutrition on lameness and claw health in cattle. Livest Sci. 2013;156(1-3):71-87.

Lietzan AD, St Maurice M. A substrate-induced biotin binding pocket in the carboxyltransferase domain of pyruvate carboxylase. J. Biol Chem. 2013;288(27):19915-25.

Livesey CT, Laven RA. Effects of housing and intake of methionine on the growth and wear of hoof horn and the conformation of the hooves of first-lactation Holstein heifers. Vet Rec. 2007;160(14):470-6.

McDonald P, Edwards RA, Greenhalgh JFD, Morgan CA, Sinclair L, Wilkinson RG. Animal nutrition. 7 ed. New York: Pearson; 2010. 692 p. 
Meckfessel MH, Brant S. The structure, function, and importance of ceramides in skin and their use as therapeutic agents in skin-care products. J Am Acad Dermatol. 2014;71(1):177-84.

Muelling CKW. Nutritional influences on horn quality and hoof health. Adv Dairy Technol. 2009; 21:283-91.

Mülling CK, Bragulla HH, Reese S, Budras KD, Steinberg W. How structures in bovine hoof epidermis are influenced by nutritional factors. Anat Histol Embryol. 1999; 28(2): 103-8.

Mülling CK, Budras KD. The hoof. In: Budras KD, Habel RE (EE.). Bovine anatomy. Hannover: Schlutersche ; 2011. p. 26-7.

Murray RK, Bender DA, Botham KM, Kennelly PJ, Rodwell VW, Weil PA. Harper's illustrated biochemistry. 29 ed. Nova York: McGraw-Hill Medical; 2012. 818 p.

NRC, National Research Council. Nutrient requirements of dairy cattle. 7 ed. Washington: National Academy of Sciences; 2001.408 p.

Queiroz PJB. Suplementação com biotina no crescimento do casco e no metabolismo energético de bezerras [dissertação]. Goiânia: Universidade Federal de Goiás; 2017.83 p.

Räber M, Geyer H, Kessler J, Gutzwiller A. Effects of high selenium intake on selenium status, liver function and claw health of fattening bulls. Schweiz Arch Tierheilkd. 2008;150(2):57-67.

Randhawa SS, Dua K, Randhawa CS, Randhawa SS, Munshi SK. Effect of biotin supplementation on hoof health and ceramide composition in dairy cattle. Vet Res Commun. 2008;32(8):599-608.

Randhawa SS, Dua K, Singh RS, Dhaliwal PS, Sharma AK. Effect of supplementation of zinc methionine on claw characteristics in crossbred cattle. Indian J Anim Sci. 2012;82(3):304-8.

Sadeghi-Nasab A, Zolhavarieh SM, Aliarabi H, Dadmehr B, Bahari A, Zamani P, et al. Assessment of the serum zinc, copper, $\beta$-carotene and vitamin $A$ and hoof zinc and copper status in different locomotion scores of dairy cattle. Iran J Vet Res. 2013;14(4):277-82.
Seyrek K, Yaylak E, Aksit H. Serum sialic acid, malondialhehyde, retinol, zinc, and copper concentrations in dairy cows with lameness. Bull Vet Inst Pulawy. 2008; 52:281-4.

Shetty S, Gokul S. Keratinization and its disorders. Oman Med J. 2012;27(5):348-57.

Silva LAF, Franco LG, Atayde IB, Cunha PHJ, Moura MI, Goulart DS. Effect of biotin supplementation on claw horn growth in young, clinically healthy cattle. Can Vet J. 2010;51(6): 607-10.

Suttle NF. Mineral nutrition of livestock. 4 ed. Cambridge: CAB International; 2010. 579 p.

Thandrayen H, Pettifor JM. The roles of vitamin D and dietary calcium in nutritional rickets. Bone Rep. 2018; 8:81-9.

Tomlinson DJ, Mülling $\mathrm{CH}$, Fakler TM. Invited review: formation of keratins in the bovine claw: roles of hormones, minerals, and vitamins in functional claw integrity. J Dairy Sci. 2004;87(4):797-809.

Voet D, Voet JG. Biochemistry. 4 ed. New York: John Wiley \& Sons; 2011. 1428 p.

Yamane M, Sugimura K, Kawasaki H, Tatsukawa H, Hitomi K. Analysis on transglutaminase 1 and its substrates using specific substrate peptide in cultured keratinocytes. Biochem Biophys Res Commun. 2016;478(1):343-8.

Zhao XJ, Wang XY, Wang JH, Wang ZY, Wang L, Wang ZH. Oxidative stress and imbalance of mineral metabolism contribute to lameness in dairy cows. Biol Trace Elem Res. 2015;164(1):43-9.

Zhang D, Arola DD, Reprogel RK, Zheng W, Tasch U, Dyer RM. A method for characterizing the mechanical behaviour of hoof horn. J Mater Sci. 2007; 42(4):1108-15. 